\title{
Extraction and Analysis of Bioactive Compounds from Dipsacus Fullonum and Galium Verum for Lyme Borreliosis Treatment
}

\author{
Maria Kuhtinskaja and Merike Vaher* \\ Institute of Chemistry and Biotechnology, Tallinn University of Technology, Estonia
}

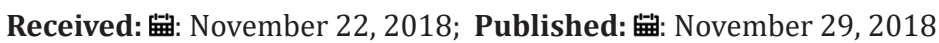

*Corresponding author: Merike Vaher, Institute of Chemistry and Biotechnology, Estonia

\begin{abstract}
Four different methods for the extraction of bioactive compounds from the two medicinal plants were compared. Based on qualitative analysis and comparison of chromatograms, all extracts can be characterized by a high content of polyphenols and iridoids. The identification of major bioactive compounds in both plant extracts were carried out using HPLC-MS analysis. More than fifteen different constituents were identified. The highest amount of iridoid glucosides were observed in Dipsacus samples.

Keywords:Bioactive Compounds, Dipsacus Fullonum, Galium Verum, HPLC-MS, Extraction, Lyme Borreliosis

Abbreviations: HWE - Hot Water Extraction; PHWE - Pressurized Hot Water Extraction
\end{abstract}

\section{Introduction}

Lyme borreliosis, although new, is the most common zoonotic disease in Europe, with an estimated 650000 - 850000 cases total and a higher incidence rate in Central Europe [1]. Treatment with antibiotics is not always effective [2] therefore, it seems logical to turn to medicinal plants for new treatment options. Liebold et al. showed that lipophilic extract from Dipsacus sylvesteris has activity against Borrelia burgdorferi [3]. Dipsacus fullonum has been used as a case study to show a promising herb that simply has no research on whether it helps people with Lyme borreliosis or any tick-borne infection [4]. Several herbal lymphatics, including Galium verum, can also be used for treatment [5]. Iridoids and polyphenols are present in many medicinal plants and their strong anti-inflammatory effects have been proven [6].

Extraction is the crucial first step in the analysis of medicinal plants. It is necessary to extract these desired chemical components from plants for further separation and characterization. For extraction, different methods were used. Mazina et al. successfully used $80 \%$ methanol and ultrasonic bath for the extraction of bioactive compounds from medicinal plants [7]. The aim of the study was to compare the different extraction methods, determine the most suitable for the extraction of bioactive compounds, and identify the major constituents.

\section{Materials and Methods}

Extraction Procedure: $1 \mathrm{~g}$ of dried plant was treated with $10 \mathrm{ml}$ of $80 \%(\mathrm{v} / \mathrm{v})$ methanol or $70 \%(\mathrm{v} / \mathrm{v})$ ethanol and sonicated for $30 \mathrm{~min}$ at $40{ }^{\circ} \mathrm{C}$. For Hot Water Extraction (HWE) - $10 \mathrm{~mL}$ of boiling water was added to $1 \mathrm{~g}$ of plant material and sonicated for $30 \mathrm{~min}$ at $80^{\circ} \mathrm{C}$. Pressurized Hot Water Extraction (PHWE) was carried out using $100 \mathrm{~mL}$ autoclave, produced by NWA analytics Meßgeräte GmbH. $6 \mathrm{~g}$ of dried material and $60 \mathrm{~mL}$ of water were loaded into the reactor. Extraction was carried out for $30 \mathrm{~min}$ at 80 bar and $100{ }^{\circ} \mathrm{C}$. All obtained extracts were centrifuged for $15 \mathrm{~min}$ at $4000 \mathrm{rpm}$ and the supernatant was diluted in accordance with needs.

\section{Results and Discussion}

The efficiency of the extraction methods was evaluated by quantitative analysis of four phenolic compounds - chlorogenic acid, rutin, protocatechuic acid and caffeic acid. The obtained results did not clearly favor one method. HWE and PHWE provided the most effective extraction of chlorogenic acid $(6.9 \pm 0.3 \mathrm{mg} / \mathrm{g}$ and $6.7 \pm 0.3 \mathrm{mg} / \mathrm{g}$ respectively) from Galium verum. At the same time, the highest yield of this acid in Dipsacus fullonum was obtained with methanolic and ethanolic extractions $(8.2 \pm 0.3 \mathrm{mg} / \mathrm{g}$ and $8.1 \pm 0.3$ 
$\mathrm{mg} / \mathrm{g}$ respectively). Protocatechuic and caffeic acids were detected only in Dipsacus samples and there are no notable differences in extraction yields between the extraction methods (except PHWE). Rutin was found only in Galium samples and the highest content of this compound was obtained with PHWE $(4.0 \pm 0.1 \mathrm{mg} / \mathrm{g})$ and methanol extraction $(3.6 \pm 0.1 \mathrm{mg} / \mathrm{g})$.

HPLC-DAD-MS was used for the characterization of the phenolic profiles in different extracts of Dipsacus fullonum and Galium verum. The identification of the compounds was done by comparison of obtained mass spectra, retention time as well as the UV spectra

Table 1: Identification of compound by HPLC-DAD-MS. with standards. In the absence of standards, identification of the compounds was carried out by careful interpretation of MS-MS data and exact measurement of precursor and fragment ions. As the chromatographic analysis shows, all extracts of the different species had a high phenolic content. Six major phenolic compounds were present in the Dipsacus samples (predominantly flavone glucosides). Additionally, a significant amount of iridoids were also detected. In Galium samples, fourteen major compounds, including quinic acid derivatives, flavonol glucosides, and iridoid glucosides, were identified. Some of the compounds were identified for the first time. The full list of identified compounds is given in Table 1.

\begin{tabular}{|c|c|c|c|c|c|}
\hline Peak & $\mathbf{R}_{t}$ (Min) & $\lambda_{\max }$ & Molecular Ion(M-H)- (M/Z) & MS-MS Data (M/Z) & Tentative Identification \\
\hline \multicolumn{6}{|c|}{ Dipsacus fullonum } \\
\hline 1 & 7.9 & 326 & 353 & 191 & Chlorogenic acid \\
\hline 2 & 9.6 & 340 & 593 & $473,431,312$ & Apigenin-di-glucoside \\
\hline 3 & 9.9 & 340 & 447 & 429,358 & Luteolin-hexoside \\
\hline 4 & 10.9 & 340 & 431 & 341,312 & Apigenin-hexoside \\
\hline 5 & 12.2 & 330 & 515 & 353 & Dicaffeoylquinic acid isomer \\
\hline 6 & 12.7 & 330 & 515 & 353 & Dicaffeoylquinic acid isomer \\
\hline 7 & 13.0 & 225 & 585 & 553,375 & Iridiod \\
\hline 8 & 13.9 & 232 & 583 & 551,373 & Sylvestroside \\
\hline \multicolumn{6}{|c|}{ Galium verum } \\
\hline 1 & 4.3 & 215 & 389 & 345 & Deacetyl-asperulosidic acid isomer \\
\hline 2 & 4.9 & 215 & 389 & 345 & Deacetyl-asperulosidic acid isomer \\
\hline 3 & 6.0 & 218 & 431 & 251 & asperulosidic acid \\
\hline 4 & 6.7 & 326 & 353 & 191 & Neochlorogenic acid \\
\hline 5 & 7.3 & 227 & 431 & 371,191 & Epi-acetylscandoside \\
\hline 6 & 7.9 & 326 & 353 & 191 & Chlorogenic acid \\
\hline 7 & 8.3 & 237 & 459 & 413 & Asperuloside glucoside \\
\hline 8 & 8.8 & 326 & 353 & 191 & Cryptochlorogenic acid \\
\hline 9 & 10.8 & 354 & 609 & 301 & Querceitin-rutinoside (Rutin) \\
\hline 10 & 11.3 & 350 & 447 & 285 & Kaempferol-glucopyranoside \\
\hline 11 & 11.9 & 354 & 623 & 315 & Isorhamnetin- rutinoside \\
\hline 12 & 12.2 & 330 & 515 & 353 & Dicoffeoylquinic acid isomer \\
\hline 13 & 12.5 & 223 & 519 & 357,191 & Iridoid glucoside \\
\hline 14 & 12.7 & 330 & 515 & 353 & Dicoffeoylquinic acid isomer \\
\hline
\end{tabular}

\section{Conclusion}

HPLC-DAD-MS is a powerful and accurate method for the separation, identification and quantification of bioactive compounds in different plants. All extraction methods are suitable for the efficient extraction of phenolic and iridoic compounds from different plant matrices. Considering that pressurized hot water and hot water extractions belong to environmentally friendly/ benign extraction methods, this type of sample treatment could be preferable.

\section{Acknowledgment}

Estonian Research Council (Institutional Research Fund No. 3320 ) is acknowledged for financial support.

\section{References}

1. http://www.europarl.europa.eu

2. Clarissou J, Song A, Bernede C, Guillemot D, Dinh A (2009) Efficacy of a long-term antibiotic treatment in patients with a chronic Tick Associated Poly-Organic Syndrome (TAPOS). Medicine et Maladies Infectiousness 39(2): 108-115.

3. Liebold T, Straubinger RK, Rauwald HW (2011) Growth inhibiting activity of lipophilic extracts from dipsacus sylvesteris huds. Roots against Borrelia burgdorferi ss in vitro. Pharmazie 66(8): 628-630.

4. Yarnell E (2016) Herbal Medicine for Lyme Disease and Other TickBorne Infections. Alternative and Complementary Therapies 22(6).

5. Wolf D Storl (2010) Healing Lyme Disease Naturally. History, Analysis and Treatment. North Atlantic Books, Berkeley, California pp. 357. 
6. V lase L, Mocan A, Hanganu D, Benedec A, Gheldiu G (2014) Comparative study of polyphenolic content, antioxidant and antimicrobial activity of four Galium species (Rubiaceae). Digest Journal of Nanomaterials and Biostructures 9(3): 1085-1094.

\section{ISSN: 2574-1241}

DOI: 10.26717/BJSTR.2018.11.002121

Merike Vaher Biomed J Sci \& Tech Res

This work is licensed under Creative Commons Attribution 4.0 License

Submission Link: https://biomedres.us/submit-manuscript.php
7. Mazina J, Vaher M, Kuhtinskaja M, Poryvkina L, Kaljurand M (2015) Fluorescence, electrophoretic and chromatographic fingerprints of herbal medicines and their comparative chemometric analysis. Talanta 139: 233-246.

$\begin{array}{ll}\text { BIOMEDICAL } & \text { Assets of Publishing with us } \\ \text { RESEARCHES } & \text { - Global archiving of articles } \\ & \text { - Immediate, unrestricted online access } \\ \end{array}$

